Jens Mastnak

\title{
Werbung und Ersatzwesen der Königlich Deutschen Legion 1803 bis 1813
}

Die neuere Forschung zur Geschichte des Militärs des beginnenden 19. Jahrhundert beschränkt sich in erster Linie auf Untersuchungen, die sich mit Preußen und den sogenannten Befreiungskriegen beschäftigen. Untersuchungen zum Militär der kleineren und mittleren deutschen Staaten fehlen fast gänzlich. Insbesondere das hannoversche Militär scheint im Dunkel der Vergangenheit verschwunden zu sein. Dies mag an dem zweifachen Traditionsbruch liegen, der die Geschichte der hannoverschen Truppen verschleiert. Nach der Einverleibung des Königreiches Hannover durch Preußen 1866 gingen die hannoverschen Truppen im preußischen Militär auf, zu einer Neubelebung hannoverscher Traditionen kam es erst 1899, als Wilhelm II. preußischen Einheiten mit hannoverschem Mannschaftsersatz die als Battle Honours vergebenen Mottos der Königlich Deutschen Legion verlieh ${ }^{1}$. Die zweite Zäsur wird durch das Ende des Ersten Weltkrieges und den Untergang des Kaiserreichs markiert. Andererseits war die Königlich Deutsche Legion, im Gegensatz zu anderen Foreign Corps der britischen Krone, ein integraler Bestandteil der britischen Armee und fand seit jeher mehr Interesse bei britischen Historikern, als ihren deutschen Kollegen. So ist es nicht weiter verwunderlich, daß die erste Monographie zur Geschichte der King's German Legion (KGL) von einem Briten, North Ludlow Beamish verfaßt worden ist ${ }^{2}$. Nach der Übertragung der Traditionspflege an preußische Einheiten setze eine Welle von Veröffentlichungen ein, die sich mit der KGL beschäftigten. Dadurch wurde der Weg für eine neue umfassende Darstellung bereitet, die sich auch mit ihrem organisatorischen Aufbau befaßte. Bernhard Schwertfeger widmete sein 1907 erschienenes Werk dem deutschen Kaiser ${ }^{3}$ : Obwohl Schwertfeger auch die inneren Verhältnisse der KGL berücksichtigte, standen die kriegsgeschichtlichen Ereignisse im Vordergrund. Selbst Daniel Savage Gray behandelt in seiner 1970 erschienen Dissertation nur diesen Aspekt, wobei er sich zudem nur auf den Dienst der Legion unter dem Befehl Wellingtons beschränkt ${ }^{4}$. Der folgende Aufsatz, der sich mit der Werbung und dem Ersatzwesen der KGL beschäftigt, ist ein Teil meines Dissertationsprojektes »Die Königlich Deutsche Legion 1803-1816 - Mentalitäten, Sozialstruktur und Kriegserfahrung«.

1 Peninsula-Waterloo war den meisten Legionseinheiten gemeinsam, Garzia Hernandez, Göhrde und Venta del Pozo waren andere Battle Honours. Vgl. dazu: Bernhard Schwertfeger, Peninsula-Waterloo. Zum Gedächtnis der Königlich Deutschen Legion, hrsg. vom Ausschuß zur Errichtung eines Denkmals zu Ehren der Königlich Deutschen Legion zur Förderung des Denkmalzweckes, Hannover 1914, S. 10.

2 Vgl. North Ludlow Beamish, Geschichte der Königlich Deutschen Legion, 2 Bde, Berlin 1906.

3 Vgl. Bernhard Schwertfeger, Geschichte der Königlich Deutschen Legion 1803-1816, 2 Bde, Hannover, Leipzig 1907.

4 Vgl. Daniel Savage Gray, The Services of the King's German Legion in the Army of the Duke of Wellington: 1809-1815, Diss. phil. Florida State University 1970. 
Da die militärischen Ereignisse aus der Geschichte der Königlich Deutschen Legion bereits erschöpfend, wenn auch nicht unter >modernen` Gesichtspunkten, behandelt worden sind, sollen diese nur als Rahmen dienen, um die Realität des Krieges zu Beginn des 19. Jahrhunderts darzustellen. Dazu gehören natürlich Aspekte wie Ernährung, Kleidung, Besoldung etc., also auch und gerade die Dinge des alltäglichen Lebens innerhalb der KGL. Diese Zielsetzung macht deutlich, daß es sich nicht um eine rein militärgeschichtliche Arbeit handelt, sondern die "Alltagsgeschichte«, oder präziser, Mikrogeschichte im Mittelpunkt stehen soll. Ein wichtiger Aspekt wird auch die Frage nach den Eintrittsmotivationen in die Königlich Deutsche Legion sein. Hier muß natürlich untersucht werden, wie die Freiwilligen geworben wurden. Außerdem läßt sich gerade am Beispiel der KGL exemplarisch die Werbung von Freiwilligen zu Beginn des 19. Jahrhunderts darstellen. Die Legion warb Freiwillige unter verschiedenen Bedingungen: Öffentlich und mit Billigung der Landesherrschaft, unter Kriegsgefangenen und heimlich in Norddeutschland während der Jahre 1803 bis 1807. Mit Ausnahme einiger Arbeiten von britischen Autoren ist die Werbung und das Ersatzwesen zu Beginn des 19. Jahrhunderts kaum untersucht worden ${ }^{5}$. Auch für andere Epochen sind wir über die Details, wie Männer tatsächlich geworben wurden, kaum unterrichtet.

Die Recherche zur Königlich Deutschen Legion kann sich auf die umfassenden Bestände des Niedersächsischen Hauptstaatsarchivs Hannover stützen. An erster Stelle ist hier der Bestand Hann. 38 D zu nennen, der einen großen Teil der dienstlich und privat entstandenen Schriftstücke der Legion umfaßt. Außerdem können zu einigen Teilaspekten die Bestände Hann. 9f (Geheime Registratur, den frz. Revolutionskrieg und die frz., preuß. und westf. Besitznahme betr. 1792-1825), Hann. 41 (Akten des Generalkommandos mit Militärakten der Londoner Kanzlei 1629-1864), Hann. 42 (Akten der königl. Generaladjutantur 1814-1866), Hann. 48 a II (Stammrollen u. Tagebücher der hannoverschen Truppenteile 1733-1867), Hann. 83 (enthält u.a. Kirchenbücher der Königlich Deutschen Legion) und Hann. 91 (Akten aus dem Nachlaß von Beamten und anderen Personen) wichtige Informationen liefern.

\section{Die Auflösung der kurhannoverschen Armee 1803}

Die hannoversche Armee bestand 1803 aus 11 Kavallerie- und 13 Infanterieregimentern, einem Artillerieregiment und dem Ingenieurkorps. Insgesamt hätte sie eine Kopfstärke von 16739 Mann haben sollen, doch fehlten im März 1803 bei der Infanterie und Artillerie 24 Offiziere, 23 Unteroffiziere, 34 Spielleute und 600 Soldaten, bei der Kavallerie 141 Reiter und 500 Pferde $^{6}$.

Nachdem eine französische Armee unter Mortier 1803 Hannover besetzt und die hannoversche Armee sich gemäß der Konvention von Sulingen kampflos hinter die Elbe zurückgezogen hatte, wurde zwischen ihr und den Franzosen die Kon-

5 Zu nennen sind hier: Anthony Brett-James, The British Soldier in the Napoleonic Wars 1793-1815, London 1970 und Philip J. Haythornthwaite, The Armies of Wellington, London 1994.

6 Vgl. Schwertfeger, Geschichte (wie Anm. 3); Bd 1, S. 9. 
vention von Artlenburg geschlossen. In ihr wurde festgelegt, daß die hannoversche Armee die Waffen niederzulegen habe und alle Truppenpferde und die gesamte Artillerie den Franzosen zu übergeben seien. Die Soldaten sollten durch Ehrenwort verpflichtet werden, so lange nicht gegen Frankreich oder seine Verbündeten zu kämpfen, bis sie nach gleichem Maßstab durch eine gleiche Anzahl französischer Armeeangehöriger ausgewechselt worden seien. Sie wurden von den Franzosen als Kriegsgefangene im eigenen Land betrachtet.

Die Angehörigen der Armee durften sich zwar an ihre Wohnorte begeben, jedoch nicht den Kontinent verlassen. In der Artlenburger Konvention wurde weder die Geldabfindung der Mannschaften angesprochen, noch wurde das hier verlangte Ehrenwort tatsächlich abgenommen. Der Wortlaut der Konvention wurde den Truppen nicht öffentlich bekanntgegeben; viele Soldaten und Offiziere erhielten erst durch den Abdruck in Zeitungen davon Kenntnis ${ }^{7}$. Die kurhannoversche Armee löste sich wenig geordnet auf: Mannschaften und Offiziere gingen einfach nach Hause. Von der Regierung in Hannover wurden allerdings einige Vorkehrungen getroffen, um zumindest den Offizieren den Heimweg zu erleichtern: Sämtliche Ämter wurden im Juli 1803 angewiesen, für die Offiziere und deren Gepäck Reitpferde und Wagen zur Verfügung zu stellen ${ }^{8}$. Die anderen hatten selbst für ihre Beförderung zu sorgen.

\section{Die Aufstellung der Königlich Deutschen Legion}

\section{Die Anfänge}

Unterdessen waren der königliche Marstall und anderes Privateigentum des Kurfürsten von Hannover nach Mecklenburg transportiert worden, um dort auf britische Schiffe verladen zu werden. An Bord eines der Schiffe, die am 19. Juli von England abgesegelt waren, befand sich der Sekretär der deutschen Kanzlei in London, Louis Möller. Bei seiner Ankunft fand er viele Offiziere der aufgelösten Armee vor, denen er mitteilen konnte, daß alle britischen Schiffe längs der deutschen Küste hannoversche Soldaten aufnehmen und nach England transportieren würden. Dort würde der Adjutant des Herzogs von Cambridge für alles weitere sorgen. Diese Nachricht verbreitete sich schnell unter den Offizieren und markierte den Beginn eines zunächst unkoordinierten Zustroms ehemaliger hannoverscher Offiziere nach England ${ }^{9}$.

Inzwischen bemühte sich Major Friedrich von der Decken um die Aufstellung eines Ausländerkorps in britischen Diensten. Er war als Adjutant des Herzogs bereits im März 1803 nach England gegangen, um Georg III. über die Lage des Kurfürstentums zu informieren. Ab 1795 war Decken Oberadjutant des Herzogs von Cambridge.

7 Zu den Konventionen von Sulingen und Artlenburg vgl. Niedersächsisches Hauptstaatsarchiv Hannover (HStA), Hann. 41 II D und C.

8 Vgl. Stadtarchiv Nienburg, 0/41.

9 Vgl. Beamish, Geschichte (wie Anm. 2), Bd 1, S. 71 f. 
Bei der Aufstellung eines Fremdenkorps in englischen Diensten lag es nahe, das militärische Potential der kleinen, aber gut ausgebildeten kurfürstlichen Armee zu nutzen. Ein weiterer Grund Deckens, sich um einen Werbebrief des Königs zu bemühen, lag sicherlich in den finanziellen Vorteilen, die damit verbunden waren. Seine Bemühungen waren erfolgreich, auch dank der Vermittlung seines Gönners, des Herzogs von Cambridge. Am 28. Juli 1803 wurde er unter gleichzeitiger Beförderung zum Oberstleutnant mit der Aufstellung eines Foreign Corps beauftragt.

Am selben Tag erhielt Major Colin Halkett, der aus holländischen Diensten nach England gekommen war, einen ähnlichen Werbebrief, der ihn ermächtigte, ein Infanteriebataillon mit einer Stärke von 459 Mann aufzustellen. Ihm wurde die Beförderung zum Oberstleutnant in Aussicht gestellt, wenn es ihm gelänge, diese Einheit auf 800 Mann zu vergrößern ${ }^{10}$.

Decken durfte insgesamt bis zu 4000 Mann werben, die unter folgenden Konditionen in den Dienst Georgs III. treten sollten: Die Rekruten sollten nicht älter als 35 Jahre alt, nicht kleiner als ca. 1,57 m und natürlich gesund genug sein, um den dienstlichen Anforderungen zu genügen. Die Dienstzeit betrug sieben Jahre - sollte Großbritannien innerhalb dieser Zeit Frieden schließen, würde der Dienst sechs Monate später enden. Geworben werden durften Männer aus allen europäischen Ländern mit Ausnahme von Franzosen, Italienern, Spaniern und Untertanen seiner britannischen Majestät. Die Legionäre wurden den britischen Soldaten bezüglich Vergünstigungen und Bezahlung gleichgestellt und unterlagen ebenso wie ihre britischen Kameraden den Kriegsartikeln. Mit der Eintrittserklärung in die Legion leisteten sie einen Eid auf den König und verpflichteten sich, überall dort zu dienen, wo die britische Regierung ihre Dienste benötigte. Wie bei britischen Soldaten wurde für den Fall der Dienstunfähigkeit aufgrund von im Einsatz zugezogenen Verwundungen oder Krankheit eine Pension gezahlt. Decken erhielt die Summe von $£ 1000$, um mit der Werbung beginnen zu können. Für jeden Rekruten, der das Depot in Lymington erreichte und dort angenommen werden sollte, erhielt er nochmals 15 Guinees $^{11}$.

Davon gingen aber das Handgeld für den Rekruten, Transportkosten und die Summe für die sogenannte skleine Mondierung،, die aus einem Paar Hemden, einem Paar Schuhe, einer Mütze, Haarband und Kamm bestand, ab. Die kleine Mondierung erhielten die neuen Rekruten entweder gleich bei ihrer Anwerbung zusammen mit dem Handgeld - so geschehen während der Expedition nach Norddeutschland 1805/6 - oder erst im Depot in England.

Um die Aufstellung des geplanten Korps erfolgreich ausführen zu können, wurde Decken gestattet, zwei Kapitäne, zwei Leutnants und zwei Fähnrịche (Ensigns) dem Herzog von York, Commander in Chief, vorzuschlagen. Dazu kamen noch die Offiziere für zwei Kompanien samt zehn Sergeanten und Korporalen, die zur Unterstützung der Werbung einzustellen waren. Sollten allerdings innerhalb von drei Monaten, also bis zum 28. Oktober 1803, nicht mindestens 400 Rekruten beisammen sein, behielt sich Georg III. vor, die Werbung zu beenden.

$10 \quad$ Vgl. ebd., Bd 1, S. 76.

1 HStA Hannover, Hann. 91 v.d. Decken, Nr. 1. Werbebrief Georgs III. für Friedrich v.d. Decken vom 28.7.1803. 
Anfangs schien es, als ob es tatsächlich nicht gelingen würde, innerhalb der drei Monate die nötigen Rekruten zu werben. Während an Offizieren, die sich bei Decken in London meldeten, kein Mangel herrschte, waren bis zum 8. August nur sieben Gemeine angeworben ${ }^{12}$. Dies war wohl auch nicht anders zu erwarten gewesen, denn schließlich mußte erst eine Organisation zur Werbung aufgebaut werden. Der Erlaubnis gemäß erhielten folgende Offiziere ihr Patent, das mit der Gazettierung am 3. September 1803 gültig wurde:

- Friedrich von der Decken als Oberstleutnant

- die ehemaligen Leutnants Johann Heiliger und Johann von Bülow als Rittmeister

- Peter de Salve und Thomas Harward ${ }^{13}$ als Leutnants

- der ehemalige Cornet im 4. Kavallerieregiment August Heise und Ludwig Cropp als Fähnriche.

Hinzu kamen noch eine Anzahl Werbeunteroffiziere ${ }^{14}$. Noch bevor die Gazettierung erfolgt war, wurde Heiliger zur Werbung via Harwich nach Deutschland geschickt ${ }^{15}$. Im Hafen von Harwich traf er am 31. Juli 1803 Heinrich von Hinüber, Wilhelm Offeney und Gabriel Heise, die vermutlich erst kurz zuvor eingetroffen und auf dem Weg zu Decken waren. Dieser organisierte unterdessen in London ein Werbehaus und schickte zwischen dem 5. und 8. August Hinüber nach Plymouth und Heise nach Harwich, wo sie die ankommenden Mannschaften und Offiziere sammeln und ihnen weiterhelfen sollten. De Salve begab sich nach Lymington, um sich dort um die Unterbringung der Mannschaften und die Aufstellung der ersten Stämme des neuen Verbandes zu kümmern. In Lymington wurden die Rekruten ärztlich untersucht und, sobald sie für tauglich befunden waren, mit der kleinen Mondierung versehen. Diese Vorgehensweise war die Regel, doch wurden die während der Expedition nach Hannover im Lande Angeworbenen bereits dort ärztlich visitiert und mit der kleinen Mondierung ausgestattet $^{16}$.

In Plymouth und Harwich wurden die Rekruten empfangen, die über die Nordsee aus Deutschland kamen. Hinüber versuchte in Plymouth auch Kriegsgefangene zu werben, die im Hafen auf Schiffen zusammengepfercht waren ${ }^{17}$. So schrieb

12 Vgl. Beamish, Geschichte (wie Anm. 2), Bd 1, S. 76 und Schwertfeger, Geschichte (wie Anm. 3), Bd 1, S. 20.

13 Schwertfeger gibt in seiner Bestandsliste des Offizierkorps der KGL das Datum seines Patentes mit 15.11.1803 an, allerdings mit dem Hinweis: , Vorher Leutnant im King's German Regiment،. Vgl. Schwertfeger, Geschichte (wie Anm. 3), Bd 2, S. 132.

14 Vgl. HStA Hannover, Hann. 38 D, Nr. 237: Die zur Geschichte der Legion gehörigen Papiere, Korrespondenzen, Orders usw. 1803-1816, Pag. 118. Beamish irrte, wenn er angab, v. Hinüber, Offeney und Gabriel Heise seien die ersten Offiziere gewesen, die sich v.d. Decken żur Verfügung stellten. Vgl. Beamish, Geschichte (wie Anm. 2), Bd 1, S. 76.

15 Nach Poten war Heiliger der erste Werbeoffizier in Husum. Vgl. Bernhard von Poten, Des Königs Deutsche Legion 1803 bis 1816, Nachdr. des 11. Beiheftes zum MilitärWochenblatt 1905, Osnabrück 1984, S. 3.

16 Vgl. HStA Hannover, Hann. 38 D, Nr. 1269: Korrespondenz des Generals v.d. Decken mit Oberstlt. v. Hedemann 1804-1805.

17 Hier warb v. Hinüber bereits im August und September 1803 Portugiesen, Dänen, Österreicher und Norweger für die Legion an. Vgl. HStA Hannover, Hann. 38 D, Nr. 96: Briefwechsel zwischen v. Hinüber und F. v.d. Decken in den Monaten August/September 1803. 
er am 15. August 1803 an Decken: »We have engaged twelve Men among the Prisoners of War. Eight of them are Portugese, two Dutch, 1 Amerikan, 1 Venetien ${ }^{18}$."

In den Briefen Hinübers an Decken wird die Sorge deutlich, was passieren würde, wenn es nicht gelänge, innerhalb der gesetzten Frist genügend Männer zu werben. Aus diesem Grund wurde auf alle möglichen Rekrutierungspotentiale zurückgegriffen, auch wenn es sich bei den Rekruten nicht um Hannoveraner; ja nicht einmal um Deutsche handelte. Die Kriegsgefangenen ergriffen natürlich jede Chance, den Zuständen in den Gefängnissen oder auf den Prison Ships zu entkommen ${ }^{19}$.

Um ankommende Offiziere und Mannschaften auf das Rekrutierungskommando aufmerksam zu machen, wurden in der ganzen Stadt Plakate angeschlagen. Mit dem Erfolg, daß sich auch ein, wie Hinüber schrieb, englischer Gentleman als Rekrut meldete, der nicht angenommen werden durfte, da Georg III. untersagt hatte, britische Untertanen zu rekrutieren ${ }^{20}$.

Am 10. August erließ der Herzog von Cambridge einen Aufruf, der sich an alle Ausländer und insbesondere Deutsche richtete, sich für das aufzustellende Korps anwerben zu lassen ${ }^{21}$. Nachdem die Nachricht von der Werbung Deckens auch Hannover erreicht hatte, verstärkte sich der Strom von Rekruten zusehends. Außerdem wurden in britischen Regimentern dienende Deutsche an die Rekrutierungskommandos überwiesen ${ }^{22}$. Anfang Oktober war das Depot in Lymington so überfüllt, daß 169 Mann unter dem Kommando des Leutnants von Bülow in die Kasernen von Parkhurst auf der Insel Wight verlegt wurden ${ }^{23}$. Zu diesem Zeitpunkt war es auch nicht mehr nötig, die Rekruten durch Offiziere in Plymouth und Harwich in Empfang zu nehmen - es genügten wahrscheinlich die dort stationierten Unteroffiziere zur Weiterleitung. Die Kommandos wurden abgezogen, und Hinüber übernahm am 13. Oktober 1803 den Befehl über das auf der Insel Wight stationierte Korps, das jetzt den Namen King's German Regiment trug ${ }^{24}$.

Bereits am 5. November erhielt Hinüber die Mitteilung von Decken, daß nunmehr der Plan, nur ein leichtes Infanterie-Bataillon aufzustellen, geändert worden sei: Nun sollte ein Korps aller drei Waffengattungen gebildet werden. Dazu wurden die Rekruten, die bereits in der Artillerie und Kavallerie gedient hatten, herausgezogen, um Kader für die beiden anderen Truppenteile zu bilden. Die übrigen auf der Insel Wight stationierten Mannschaften sollten das 1. Bataillon bilden, die bereits von Halkett geworbenen ein zweites ${ }^{25}$.

Zwischen Halkett und Decken war am 6. Oktober ein Abkommen geschlossen worden, in dem festgelegt wurde, die Werbungen zusammenzulegen. Das leichte Bataillon Halketts sollte nun eines der King's Germans werden, und die gedienten

Ebd., Pag. 34. v. Hinüber an v.d. Decken 15.8.1803. Bei fehlerhafter Schreibweise innerhalb der Zitate habe ich auf das übliche "[sic]« verzichtet, da viele der folgenden deutschen und englischen Zitate teilweise erheblich von der heutigen Schreibweise abweichen und eine Kennzeichnung diese Texte sehr unübersichtlich werden ließe. Vgl. ebd. v. Hinüber an v.d. Decken 17.8.1803.

Ebd.

${ }^{21}$ Vgl. HStA Hannover, Hann. 38 D, Nr. 237, Pag. 77/78: Proklamation des Herzogs von Cambridge vom 10.8.1803.

22 So trafen 21 Mann des 95. Regiments am 28.9.1803 bei Hinüber in Plymouth ein. Vgl. HStA Hannnover, Hann. 38 D, Nr. 96.

23 Vgl. HStA Hannover, Hann. 38 D, Nr. 237, Pag. 121.

24 Vgl. Beamish, Geschichte (wie Anm. 2), Bd 1, S. 78.

25 Vgl. HStA Hannnover, Hann. 38 D, Nr. 237, Pag. 122. 
Artilleristen und Kavalleristen wurden ebenfalls zur Aufstellung der Kavallerie und der Artillerie abgestellt. Nach dem Abkommen mußte Halkett 200 Mann liefern, um mit dem permanenten Rang als ältester Major der King's Germans ausgestattet zu werden. Jede weitere Rekrutierung in Deutschland durch Halkett sollte nach Erfüllung des geplanten Werbeumfangs eingestellt und alle weitere Werbung Decken überlassen werden. Halkett sollte als Oberstleutnant das neu aufgestellte Bataillon kommandieren. Sollte die Rekrutierung für die King's Germans so erfolgreich sein, daß mehrere Obristenposten zu vergeben sein würden, würde Halkett zum Oberst befördert, allerdings konnte der Herzog von Cambridge nicht zusichern, daß dies ein permanenter Rang sein würde ${ }^{26}$.

So bildeten beide Werbungen ab Ende Oktober 1803 den Stamm der späteren King's German Legion ${ }^{27}$. Bereits am 19. Dezember konnten rund 1000 Mann bei Portsmouth zusammengezogen werden, und Georg III. ernannte seinen jüngsten Sohn Adolph Friedrich, Herzog von Cambridge, nun offiziell zum Colonel in Chief. Seitdem wurde die Truppe The King's German Legion genannt.

\section{Werbung in Norddeutschland $1803-1805$}

Zum weiteren Aufbau der KGL mußte nun ein Apparat geschaffen werden, der es ermöglichte, möglichst viele ehemalige Soldaten der kurhannoverschen Armee und sonstige Freiwillige für die Legion werben zu können. Decken hatte natürlich ein Interesse daran, möglichst viele Rekruten zu werben, da er an jedem Rekruten, der auf seine Rechnung geworben wurde, zwischen 7 und 8 Guinees verdiente. Viele ehemalige Offiziere der kurhannoverschen Armee betätigten sich in ihrer Heimat als Werber. Einige wandten sich an Decken mit dem Vorschlag, eine bestimmte Anzahl von Männern zu werben, um dann in England die neu aufzustellende Einheit, sei es eine Kompanie oder ein Bataillon, zu kommandieren. In England angekommen, erhielten viele tatsächlich das gewünschte Kommando.

Da das Kurfürstentum von den Franzosen besetzt war, konnten kaum Rekruten in größerer Zahl über die hannoverschen Nordseehäfen außer Landes geschafft werden. Die in den Häfen Ritzebüttel und Bremerlehe ansässigen britischen Kaufleute begaben sich nach der Besetzung dieser Häfen nach Helgoland und etablierten von dort aus einen neuen Handelsweg über Husum und Tönningen ${ }^{28}$. Durch diese regelmäßige Verbindung via Helgoland bot sich Husum als Standort zur Koordinierung der Werbung in Hannover an. Zudem gehörte Husum zu Dänemark; die dänische Regierung schien die Werber mehr oder weniger in Ruhe ihrem Geschäft nachgehen zu lassen.

26 Vgl. HStA Hannover, Hann. 38 D, Nr. 191: Papiere, die Beförderung von Offz. im 2. leichten Bataillon betreffend und die Bedingungen, unter welchen Gen. v. Halkett am 17.11.1803 in die Legion eintrat, Pag. 11/12, Hann. 38 D, Nr. 1, Pag. 5-7 und Beamish (wie Anm. 2), Bd 1, S. 80. Während in Hann. 38 D, Nr. 1 das Datum mit 6.10. angegeben ist, wurde in Nr. 191 nachträglich der 26.10. eingefügt. Da es sich bei Nr. 191 wahrscheinlich um eine Abschrift handelt, erscheint der 6.10. wahrscheinlicher.

27 Vgl. Beamish, Geschichte (wie Anm. 2), Bd 1, S. 80.

28 Vgl. Friedrich von der Decken, Philosophisch-historisch-geographische Untersuchungen über die Insel Helgoland oder Heiligeland und ihre Bewohner, Hannover 1826, S. $185 \mathrm{f}$. 
Der Rittmeister Heiliger etablierte eine Organisation, die Rekruten aus dem Hannoverschen über Hamburg nach Husum schaffte, wo sie gesammelt und über Helgoland nach England geschickt wurden. In Hamburg wurden die Rekruten in dieser Anfangsphase von dem Oberpostmeister Johanns weiter geleitet ${ }^{29}$. Während Hamburg die zentrale Anlaufstelle für einen Großteil der Rekruten aus dem norddeutschen Raum wurde, entwickelte sich die Organisation in Husum zur Schaltstelle der gesamten Werbung. Gleichzeitig waren in den Ostseehäfen ebenfalls Offiziere stationiert worden, die dort ankommende Rekruten weiterleiteten $^{30}$. In Husum liefen alle Informationen über die Werbung zusammen: die Meldungen der Werber über die Verhältnisse im Lande, über mögliche Schwierigkeiten oder auch die erfreulichen Nachrichten, daß mehrere hundert Rekruten zu erwarten seien. Der Werbeoffizier in Husum meldete alle Neuigkeiten samt seiner persönlichen Einschätzung direkt an Decken und empfing von ihm entsprechende Weisungen.

Heiliger übergab die Geschäfte im April 1804 wahrscheinlich direkt an Heinrich v. Hinüber. Dieser war zusammen mit dem Hauptmann Nanne zur Werbung des 3. Linienbataillons nach Husum gesandt worden ${ }^{31}$. Am 21. September 1804 wurde Hinüber von Major Carl von Reinbold abgelöst. Einem Befehl Deckens folgend, übernahm der Leutnant Friedrich Ludwig Meyer die Rechnungs- und Geldangelegenheiten ${ }^{32}$. Unterstützt wurden Reinbold und Meyer insbesondere vom ehemaligen Quartiermeister der kurhannoverschen Armee Haacke, der im Gegensatz $z u$ den anderen anwesenden Unteroffizieren im Lesen und Schreiben geübt war ${ }^{33}$.

Später wurden dann immer einige Unteroffiziere, die schreibkundig waren, zur Anfertigung von Listen oder Instruktion der ankommenden Mannschaft eingesetzt. Reinbold hoffte durch seine Rekrutierungsarbeit auf dem Kontinent das gesamte neu aufzustellende 4. Linienbataillon zu werben und als Anerkennung sein Kommandeur zu werden. Als dies nicht geschah, machte er gegenüber Decken keinen Hehl aus seiner Enttäuschung ${ }^{34}$.

Obwohl seinen Wünschen nicht entsprochen wurde, bemühte er sich weiterhin, der KGL möglichst viele Rekruten zu verschaffen und bot Decken an, dafür zu bürgen, daß ein Rekrut bis zu seiner Ankunft in Harwich nicht mehr als $€ 8$ an Kosten verursachen solle. Immerhin waren von den insgesamt $746 \mathrm{Mann}$, die zwischen September und Oktober 1804 Husum verließen, 183 von Reinbold direkt geworben worden ${ }^{35}$. Diese große Zahl von Rekruten mußte in Husum und Umgebung so lange beherbergt und verpflegt werden, bis eine Transportmöglichkeit organisiert war. Meistens waren dies die Paketboote, die von Helgoland kommend regelmäßig Husum anliefen. Zur Unterbringung der Leute hatte Reinbold Verein-

Vgl. Poten, Des Königs Deutsche Legion (wie Anm. 15), S. 3 und Schwertfeger, Geschichte (wie Anm. 3), Bd 1, S. 20.

30 Vgl. HStA Hannover, Hann. 38 D, Nr. 237, Pag. 54.

31 Vgl. HStA Hannover, Hann. 38 D, Nr. 815: Journal des 3. Linienbataillons. Das Datum der Übergabe ist gesichert, jedoch nicht, ob Hinüber der direkte Nachfolger Heiligers war.

32 Die folgenden Ausführungen zur Werbung sind dem ausführlichen Schriftwechsel zwischen v. Reinbold und v.d. Decken zwischen September 1804 und Juni 1805 entnommen. Vgl. HStA Hannover, Hann. 38 D, Nr. 107: Korrespondenz zwischen Charles v. Reinbold in Husum und Col. v.d. Decken in London betr. Werbeangelegenheiten für die Legion.

33 Vgl. ebd., Pag. 121.

34 Vgl. ebd., Pag. 22.

35 Ebd., Pag. 1. 
barungen mit verschiedenen Wirten getroffen, so daß er etwa 150 Mann gleichzeitig in Husum und Umgebung unterbringen konnte.

Aufgrund des steigenden dänischen Druckes und der Unmöglichkeit, genügend Pässe über den dänischen Gesandten in Hamburg zu bekommen, wies Reinbold Ende 1804 die in Hamburg stationierten Werber an, die Leute ins Land zurückzuschicken, da kaum mehr Möglichkeiten bestanden, sie aus Husum wegzuschaffen. Obwohl der Befehl wahrscheinlich nicht unbeachtet blieb, nahmen die Probleme mit der großen Zahl in Husum eintreffender Rekruten kaum ab. Allerdings waren die Husumer Offiziere der KGL gewitzt genug, auch mit diesen Schwierigkeiten fertig zu werden und trotz stärkerer Überwachung die Rekruten außer Landes zu schaffen $^{36}$.

Es entwickelte sich ein Katz-und-Maus-Spiel mit den Dänen, die offensichtlich zumindest bis Ende 1805 nicht ernsthaft daran dachten, die Werbegeschäfte in Husum vollständig zu unterbinden. Ganz geheim gehalten werden konnte die eigentliche Tätigkeit der Offiziere der KGL in Husum nicht. Die Wirte und Bauern, bei denen die Rekruten untergebracht wurden, werden schnell gewahr geworden sein, aus welchen Gründen sich ihre 'Gäste in der Umgebung Husums aufhielten und wohin ihre Reise ging. So konnten die Informationen über bevorstehende heimliche Einschiffungen bis zu den dänischen Behörden gelangen. Wie Reinbold selbst ausführt, spielten Bestechungen eine wichtige Rolle. Nicht nur wegkundige Bürger Husums wurden bestochen, sondern auch Mitglieder der dänischen Paßkommission, die durch Einladungen zum Essen und Geschenke nachsichtig gestimmt werden sollten. Am 6. Februar 1805 sprach Reinbold mit Leutnant Donner von der Paßkommission und kam mit ihm überein, daß immer einige Rekruten auf der >Helgoländer Schnigges, die regelmäßig zwischen Husum und Helgoland verkehrte, mitfahren sollten. Bei einer Begegnung mit dänischen Patrouillen sollten sie behaupten, auf eigene Faust nach England zu reisen. Daraufhin würden sie mit der Ermahnung entlassen, in ihr Heimatland zurückzukehren ${ }^{37}$. Trotzdem mußte Aufsehen vermieden werden, wollte man nicht riskieren, von den dänischen Behörden stärker behindert oder sogar des Landes verwiesen zu werden. Genau dies geschah aber im April 1805, als Hauptmann Heinrich Brückmann, Leutnant Johann Friedrich Oehme und der Fähnrich August v. Klencke in Husum ankamen, um die Geschäfte zu übernehmen ${ }^{38}$. Die Ankunft der Offiziere erregte bei den dänischen Behörden großes Mißtrauen, so daß sie in der Nacht vom 19. auf den 20. April 1805 alle Quartiere durchsuchten und die Pässe der dort untergebrachten Rekruten überprüften. Glücklicherweise waren mit Ausnahme eines Sergeanten alle mit solchen versehen. Der Sergeant Schuster wurde in Haft genommen ${ }^{39}$, und einem anderen Unteroffizier ging einige Tage später die Aufforderung zu, Husum innerhalb von drei Tagen zu verlassen ${ }^{40}$. Einige Rekruten wurden längere Zeit in Haft genommen, z.B. weil sie den dänischen Behörden entgegen den Instruktionen der Werbeunteroffiziere den wahren Grund ihres Aufenthaltes in Husum mitgeteilt hatten ${ }^{41}$.

\footnotetext{
6 Vgl. ebd., Pag. 52.

Ebd., Pag. 89.

Vgl. ebd., Pag. 12.

Vgl. ebd., Pag. 14.

Vgl. ebd., Pag. 163.

41 Vgl. ebd., Pag. 163.
} 
Während Reinbold dort stationiert war, benutzten sicherlich mehr als 2000 Mann den Weg über Husum, um in die KGL einzutreten ${ }^{42}$. Ein weiteres Problem, das die Werbung behinderte, waren die britischen Zeitungen, die immer wieder über die Anzahl der in Harwich landenden Rekruten berichteten. Durch diese Berichte wurden die Dänen mißtrauisch und beobachteten die deutschen Offiziere noch wachsamer. Reinbold bat daher Decken mehrfach, doch seinen Einfluß auf die Herausgeber der Zeitung geltend zu machen, um dies zu unterbinden ${ }^{43}$. Problematisch war die Lebensweise einiger Werber: Der vorzugsweise in Hamburg operierende Hauptmann Breymann wurde durch seine extravagante Art ( vermutlich verstärkt durch Alkoholkonsum ( dort dermaßen auffällig, daß Reinbold ihn ermahnte, er müsse vorsichtiger zu Werke gehen, um unnötiges Aufsehen zu vermeiden. Einige Schwierigkeiten entstanden auch dadurch, daß Offiziere, die bereits bei der KGL standen, Kontakt zu ihnen bekannten Werbern im Hannoverschen aufnahmen, um bestimmte Unteroffiziere und Mannschaften ihrer früheren Einheit zu werben. Ihr Ziel war die möglichst schnelle Aufstellung einer Einheit, was mit ausgebildeten Männern besser zu bewerkstelligen war. Der Artillerie-Hauptmann August Röttiger sandte von England aus Anweisungen an den Leutnant Sympher, der sich noch im Kurfürstentum aufhielt, spezielle Artilleristen der kurhannoverschen Armee zu werben ${ }^{44}$. Decken hatte Röttiger die Freiheit eingeräumt, eine reitende Batterie aufzustellen, die, mit ausgesuchten Mannschaften ausgestattet, beispielhaft für die Artillerie der KGL sein sollte. Selbst die Munitionswagen wurden nicht von den Briten geliefert, sondern nach dem Vorbild der französischen Wagen speziell angefertig $t^{45}$. Um die Werbung von Hannoveranern für andere Truppen zu unterbinden, ließ Reinbold durch August v. Klencke, der auf dem Weg zur Familie des Generals von Hammerstein in Preußen war, in Lübeck »unter der Hand [...] einen kleinen Aufsatz drucken [...], in welchem die Hannoveraner für der Krügerschen Werbung gewarnt werde[n] $\aleph^{46}$.

Dieser sollte dann heimlich in Hannover verteilt werden. Durch die gerade in Hamburg auffällige Art der Werbung und durch Spitzel war den Franzosen ein großer Teil der Werbeorganisation bekannt geworden ${ }^{47}$. Sie waren zu diesem Zeitpunkt nicht sonderlich daran interessiert, die Auswanderung zu unterbinden. Reinbold war sich dessen bewußt, wie aus einem Brief an Decken vom November 1804 hervorgeht. Er sei überzeugt, so schrieb er, daß den Franzosen der Gang der Wer-

Im Zeitraum vom 19.12.1803 bis zum 19.7.1808 wurden auf den Werbebrief v.d. Deckens insgesamt 5026 Mann angeworben. In dieser Summe sind nicht die während der Expedition nach Norddeutschland 1805/6 Geworbenen enthalten. Vgl. Listen und Nachweisungen welche sich auf den Dienst der Königlich Deutschen Legion von Errichtung derselben bis zu ihrer Auflösung beziehen, Hannover 1837, S. 254. Vgl. HStA Hannover, Hann. 38 D, Nr. 107, Pag. 123. Vgl. HStA Hannover, Hann. 38 D, Nr. 107, Pag. 83.

45 Vgl. Georg Heinrich Klippel, Das Leben des Generals von Scharnhorst, 2. Teil, Leipzig 1869, S. 270: Brief v.d. Deckens an Scharnhorst vom 27.6.1805.

46 Vgl. HStA Hannover, Hann. 38 D, Nr. 107, Pag. 158.

47 Reinbold schrieb am 20.5.1805 an v.d. Decken: 'Am 12ten d. M. ist der Capt. Wolkenhaar in Hameln von Gendarmerie arretiert worden, ein hessischer Deserteur, welcher sich in Hameln bey den frantz. Werbers für die frantz. Legion hat engagieren laßen, ist zu Wolkenhaar gegangen und hat sich von ihm Paß und Reise Geld nach England geben laßen, worauf dieser Schurke W. sogleich angegeben hat. Die Gendarmen haben unter W. seinen Papieren, die Marschroute nach Hamburg, die Adresse in Hamburg, das hier abzugebende Zeichen, einige Päße [...] gefunden.< Ebd., Pag. 166. 
bung ebenso bekannt sei wie ihm selbst, sie hielten es aber nicht der Mühe wert, diese zu stören ${ }^{48}$.

Insgesamt bleibt festzustellen, daß die Rekrutierung im Kurfürstentum zwischen August 1803 und Ende 1805 auf weniger Hindernisse stieß, als man hätte erwarten können. Die Nachricht von der Aufstellung der KGL in England war allgemein bekannt geworden und der Zustrom zu den Werbern war so stark, daß sich Probleme eher bei ihrer Unterbringung, einer möglichst schnellen Verschickung nach England und allzu großer >Publicität ‘ ergaben. Bei einzelnen Wanderern, die Richtung Hamburg und Husum zogen, drückte die Obrigkeit durchaus ein Auge zu. Bei Hunderten, die auf ihrem Weg nach England gemeinsam das Land durchquerten, war dies schwer möglich. Die Rekrutierung in den ersten anderthalb Jahren des Bestehens der KGL war also durchaus eine Erfolgsgeschichte. Schien es anfangs, als ob nicht ausreichend Mannschaften innerhalb von zwei Monaten angeworben werden könnten, so bestand die KGL im Januar 1805 aus 294 Offizieren, 294 Unteroffizieren, 112 Spielleuten und 5292 Mannschaften, insgesamt 5992 Mann $^{49}$.

Nachdem Reinbold seine Rechnungen und Auflistungen abgeschlossen hatte, begab er sich im Juni 1805 in Begleitung seines Sohnes wieder nach England. Sein Nachfolger in Husum war der Hauptmann Brückmann. Reinbold wurde zwar in der Folge nicht als Kommandeur des 4. Linienbataillons KGL eingesetzt, doch schließlich erreichte er sein Ziel ein Bataillon zu kommandieren, als er Chef des 5. Linienbataillons wurde.

\section{Rekrutierung während der Expedition nach Norddeutschland $1805 / 1806$}

Die erste Phase der Werbung war Mitte 1805 abgeschlossen. Im Oktober 1805 umfaßte die Legion zwei leichte, vier Linienbataillone und die Stämme für zwei weitere, ein schweres und zwei leichte Dragoner- (Husaren) Regimenter sowie zwei reitende und drei Fußkompanien Artillerie. Das Ingenieurkorps setzte sich nur aus Offizieren zusammen und bestand zu diesem Zeitpunkt aus sieben Mann. Außerdem gab es eine Garnisons- und eine Depotkompanie ${ }^{50}$.

Nachdem Rußland, Österreich, Schweden, Neapel und England 1805 eine Koalition gegen Frankreich gebildet hatten, sollte ein englisches Truppenkontingent nach Deutschland entsandt werden, das von Norden her die Operationen der alliierten Hauptarmee unterstützen sollte. Den Befehl über die englischen Truppen erhielt Lord Cathcart. Die KGL nahm mit den beiden leichten, den ersten vier Linienbataillonen, einem Teil der Artillerie und Teilen der Kavallerie an dieser Expedition teil. Durch die Zusammenziehung der französischen Truppen im Süden war Hannover mit Ausnahme der Festung Hameln frei von französischem Militär. Somit schienen die Aussichten für die KGL günstig, ihr Heimatland zu befreien.

48 Vgl. ebd., Pag. 133.

49 Vgl. Listen und Nachweisungen (wie Anm. 42), S. 250.

50. Vgl. Schütz von Brandis, Übersicht der Geschichte der hannoverschen Armee von 1617 bis 1866. Bearb. von Johann Frhr. von Reitzenstein, Hannover, Leipzig 1903, S. 27-30 und Schwertfeger, Geschichte (wie Anm. 3), Bd 1, S. 194-199. 
Militärisch gesehen war das gesamte Unternehmen der Verbündeten ein Mißerfolg. Napoleon zwang den österreichischen Feldmarschall Mack bei Ulm zur Kapitulation. Die Dreikaiserschlacht bei Austerlitz am 2. Dezember beendete praktisch den Krieg. Als das Expeditionskorps am 18. November 1805 Cuxhaven erreichte, lag die Kapitulation Macks bereits mehr als einen Monat zurück. Für die KGL allerdings erwies sich die Expedition in organisatorischer Hinsicht als Erfolg, da die Werbung während des Aufenthalts im Kurfürstentum höchst erfolgreich war. Dies war bereits bei der Planung berücksichtigt worden; man hatte auf den Transportschiffen Waffen und Ausrüstung für etwa 10000 Mann aus England mitgeführt ${ }^{51}$. Die einzige Feindberührung hatte das erste Linienbataillon unter Christian v. Ompteda in der Nähe Hamelns mit französischen Vorposten ${ }^{52}$.

Unverzüglich nach der Landung wurden Depots zur Aufnahme der ankommenden Rekruten eingerichtet. Das General-Depot befand sich in Stade, ein weiteres in Hannover. Die Werbung konnte nun ganz öffentlich betrieben werden, und nicht nur die bereits in der KGL Dienenden widmeten sich dieser Aufgabe, sondern auch die noch im Kurfürstentum verbliebenen Offiziere. Friedrich von der Decken organisierte auch hier den gesamten Ablauf, anfangs in Stade und später von Hannover aus ${ }^{53}$. Im ganzen Land richteten Offiziere Werbebüros ein. Dort wurden mögliche Rekruten unter anderem dadurch gelockt, daß ihnen die gut angezogenen Soldaten der KGL präsentiert wurden ${ }^{54}$.

Die Werbung lief aber nicht nur über einzelne Werber, die noch nicht in der KGL dienten, sondern auch über die gelandeten Einheiten der KGL, die ebenfalls warben. Dazu wurden einzelne Offiziere und Unteroffiziere abgestellt, die meist in größeren Orten des Landes diesem Geschäft nachgingen. Natürlich waren Rekruten auch bei der Truppe direkt willkommen ${ }^{55}$. Freiwillige strömten in so großer Zahl zu den Werbebüros und zur Truppe, daß allein bis zum 24. November 1805 insgesamt 981 Mann im Depot in Stade eintrafen ${ }^{56}$.

Nachdem sich Frankreich und Österreich im Frieden von Preßburg am 25. Dezember 1805 geeinigt hatten und sich Preußen ebenfalls von der Koalition abwandte, und gleichzeitig sein Interesse an einer Besetzung Hannover deutlich gemacht hatte, wurde beschlossen, die gelandeten britischen Truppen wieder einzuschiffen. Bereits Anfang Januar erging eine Bekanntmachung an die Truppe. Gleichzeitig erinnerten die Bataillonskommandeure ihre Soldaten und die neuen Rekruten an ihren Eid, mindestens sieben Jahre in der KGL zu dienen ${ }^{57}$. Dieser Hinweis war unter den gegebenen Umständen angebracht. Obwohl insgesamt 7876 Mann während des Aufenthalts in Norddeutschland 1805/6 angeworben worden waren ${ }^{58}$ war der Ver-

51 Vgl. Schwertfeger, Geschichte (wie Anm. 3), Bd 1, S. 32.

52 Vgl. dazu: Ludwig v. Ompteda, Das erste Linienbataillon der Königlich Deutschen Legion vor Hameln, in: Zeitschrift des Historischen Vereins für Niedersachsen, 1861, S. 343-350.

53 Vgl. HStA Hannover, Hann. 38 D, Nr. 1273: Die Werbung des Generals v.d. Decken 1805/6.

54 Vgl. HStA Hannover, Hann. 38 D, Nr. 1269: Korrespondenz des Generals v.d. Decken mit Oberstleutnant v. Hedemann 1804-1805.

55 Vgl. dazu HStA Hannover, Hann. 38 D, Nr. 815: Journal des 3. Linienbataillons, Eintrag 25.11.1805.

56 Vgl. HStA Hannover, Hann. 38 D, Nr. 1273.

57 Vgl. HStA Hannover, Hann. 38 D, Nr. 815: Journal des 3. Linienbataillons, Eintrag 20.1.1806.

58 Vgl. Schwertfeger, Geschichte (wie Anm. 3), Bd 2, S. 188: Anwerbungen für die Königlich Deutsche Legion. 
lust durch Fahnenflucht immens. Insgesamt desertierten 1442 Mann während der Expedition nach Hannover ${ }^{59}$. Obwohl sich beispielsweise das 1 . leichte Bataillon mit insgesamt 729 Mannschaften am 5. Februar wieder einschiffte, hatte es durch Desertion in der Zeit vom 31. Januar bis zur Einschiffung 245 Mann verloren ${ }^{60}$. Das 3. Linienbataillon hatte keinen so großen Verlust zu beklagen, doch auch hier beschlossen 97 Soldaten, nicht mehr nach England zurückzugehen ${ }^{61}$.

Die Ursachen für die Entscheidung zur Fahnenflucht werden im Journal des 3. Linienbataillons deutlich benannt. Beim Eintreffen in den norddeutschen Häfen hofften die Soldaten der KGL noch, dauerhaft in ihr Heimatland zurückkehren zu können. Auch die einheimische Bevölkerung erhoffte sich die Vertreibung der französischen Besatzer. Freiwillige hatten sich gemeldet, um gegen die Franzosen vorgehen zu können, möglicherweise auch in der Erwartung, die Franzosen würden nicht wieder ins Kurfürstentum zurückkehren und man könne sich ohne kriegerische Verwicklungen in die KGL einreihen, um von seinen Landsleuten als Held und Befreier bewundert zu werden. Diese Hoffnung wurde jedoch mit dem als schmählich empfundenen Rückzug zunichte gemacht. Allerdings dürfte der Rekrutierungserfolg, der trotz der Desertionswelle im Januar 1806 immens gewesen war, auch auf die offensive Werbung zurückzuführen sein. Die Desertionen setzten ein, als bekannt wurde, daß sich die englischen Truppen wieder einschiffen würden. Für die bereits in der KGL Dienenden war die Aussicht auf eine Rückkehr nach England wenig erfreulich: Hatten sie doch gehofft, wieder mit ihren Familien, die sie zum Teil seit Jahren nicht mehr gesehen hatten, zusammenleben zu können und natürlich auch ihr Vaterland zu befreien. Für den Teil der Legionäre, die es vorzogen, in der Heimat zu bleiben, statt nach England zurückzugehen, war dies sicherlich keine einfache Entscheidung, da sie bei einer Ergreifung mit empfindlichen Strafen zu rechnen hatten. Das Risiko wurde allerdings immer geringer, je näher der Tag der Einschiffung der englischen Truppen rückte.

Bei näherer Betrachtung könnte man die Desertion eines Teils der bereits gedienten Soldaten auch als einen Prozeß ansehen, der auf lange Sicht die Moral innerhalb der Truppe hob und die Bereitschaft, nicht nur auf hannoverschem Boden gegen Napoleon zu kämpfen, stärkte. Nach der Wiedereinschiffung waren Rekruten und Legionäre vorhanden, die bereit waren, die Trennung von Familie und Heimat auf sich zu nehmen oder durch die Androhung harter Strafen von der Desertion abgehalten werden konnten. Den weggelaufenen Rekruten machte sicher nicht eine Überfahrt auf der Nordsee Angst, wie im Journal des 3. Linienbataillons vermutet wird. Eher ist anzunehmen, daß sie auf heimatlichem Boden und in Kontakt zur Familie bereit waren, in der Legion zu dienen und nicht in England und schon gar nicht, wie mit hannoverschen Truppen in englischen Diensten mehrfach geschehen, in Übersee. Die Befürchtung, die Heimat auf unabsehbare Zeit nicht zu sehen, sollte für die meisten Soldaten, die im Februar 1806 in Cuxhaven an Bord

59 Vgl. Daniel Savage Gray, Prisoners, Wanderers, and Deserters: Recruiting for the King's German Legion, 1803-1815, in: Journal of the Society for Army Historical Research, 53 (1975), S. 151.

60 Vgl. HStA Hannover, Hann. 38 D, Nr. 683: Versch. Meldungen betr. Munition, Kleidung, Waffen, Zelte, Inspektion und Arbeitsabteilungen auf den Hütten zu Bexhill, Ein- und Ausschiffung, Verluste usw. Liste von Soldaten, die durch das 1. leichte Bataillon in Deutschland angeworben wurden, Pag. 40-42.

61 Vgl. HStA Hannover, Hann. 38 D, Nr. 815: Journal des 3. Linienbataillons, Eintrag 7.2.1806. 
gingen, wahr werden. Erst 1813 konnten einige derjenigen, die die Einsätze in Holland, Spanien, Portugal und Sizilien überlebt hatten, wieder nach Hannover gelangen ${ }^{62}$.

Trotz der Desertionen verblieb ein so großer Überschuß an Rekruten, daß nun in England ein zweites schweres und ein drittes leichtes Dragonerregiment, eine vierte Fußbatterie und das 5., 6. und 7. Linienbataillon sowie der Stamm des 8. formiert werden konnten ${ }^{63}$. Damit waren alle Einheiten, mit Ausnahme des Veteranenbataillons, das 1813 aufgestellt wurde, entstanden, die bis zu ihrem Ende die KGL ausmachten. Die Phase der Aufstellung war beendet, die KGL hatte im Mai eine Stärke von 13381 Mann erreich $t^{64}$. In der Folgezeit wurden keine neuen Einheiten mehr aufgestellt, jetzt ging es um die Auffüllung der durch Krankheit, Verluste auf See und Gefallene gelichteten Reihen. Im Laufe der Zeit gestaltete sich die Anwerbung neuer Rekruten immer schwieriger, zumal das Potential der Hannoveraner spätestens ab Ende 1807 kaum mehr zu erreichen oder bereits ausgeschöpft war. Die KGL mußte andere Wege der Ergänzung finden.

\section{Ersatzwesen der Königlich Deutschen Legion}

Die KGL hatte nie Schwierigkeiten, Lücken im Offizierkorps zu füllen. Temporäre Engpässe traten zwar auf, wie etwa 1810, als die Franzosen hannoversche Offiziere der KGL mit der Einziehung ihrer Güter im ehemaligen Kurfürstentum bedrohten, doch die Nachfrage nach Offizierstellen war nach Abschluß der Aufstellungsphase immer größer als der Bedarf. Für das 3. Husarenregiment stellte der Weggang einiger Offiziere ein schwieriges Problem dar, wie Ernst v. Linsingen in einem Brief vom Juni 1810 schildert:

„Die unglückliche Proclamation wegen Confiscation der Güter in Hannover trifft in dieser Zeit für unser Regt. so unglücklich wie möglich [...] Wenn alle die Officiere weggehen was soll aus dem Regiment werden und was werden die Leute davon denken, wenigstens der vermögende Theil? Werden sie es nicht hart finden daß die Officiere um ihr Vermögen zu retten - selbst vor dem Feind dienend, Erlaubniß kriegen nach Hause zu gehen wozu ihnen wenn der Termin abgelaufen jede Hofnung abgeschnitten ${ }^{65}$ ?

Diese Krisensituation konnte entschärft werden, die Drohung mit der Konfiskation der Güter wurde nicht zu einem ernst zu nehmenden Problem. In London hielten sich zeitweilig einige Dutzend ehemalige Offiziere der kurhannoverschen Armee und andere Anwärter auf, die auf Anstellung hofften. Die Bittbriefe an Decken füllten ganze Akten; die KGL konnte sich ihre Offiziere auswählen und war nicht, wie

62 Vgl. zur Desertion vor der Wiedereinschiffung der KGL 1806: Poten, Des Königs Deutsche Legion (wie Anm. 15), S. 18; Marie Ballauf, Des Königs deutsche Legion bis zur Schlacht bei Talavera, Hannover 1909, S. 69-71 und Hartmann, Der Königlich Hannoversche General Sir Julius Hartmann, Hannover 1858, S. 48.

63 Vgl. Schwertfeger, Geschichte (wie Anm. 3), Bd 1, S. 35.

64. Vgl. ebd., Bd 2, S. 184.

65 HStA Hannover, Hann. 38 D, Nr. 237, Pag. 194. Ernst v. Linsingen an Carl Christian v. Linsingen, 17.6.1810. 
in späteren Jahren, beim Ausgleich der Mannschaftsverluste auf mehr oder weniger zweifelhaften Ersatz angewiesen ${ }^{66}$.

Die Verbände der KGL wurden nie als eigenständiges Korps eingesetzt, nur die beiden leichten Bataillone und die schweren Dragoner bildeten einen ständigen Brigadeverband. Im Rahmen der britischen Armee wurden sie einzeln mit britischen Einheiten und unter britischem Kommando eingesetzt. Daraus erklärt sich auch die Vielzahl der Einsatzorte, die von Rügen bis Sizilien reichten ${ }^{67}$. Zwischen den verschiedenen Einheiten ergaben sich Differenzierungen hinsichtlich der Möglichkeiten, ihre Verluste zu ersetzen. Einige Einheiten wurden über lange Zeiträume als Garnisontruppen verwendet, während andere durch Kampfhandlungen und beschwerliche Rückzüge, wie die beiden leichten Bataillone beim Marsch auf Coruña im Winter 1808/9, schwere Verluste hinnehmen mußten. Verluste entstanden nicht nur durch Tod auf dem Schlachtfeld und Desertionen, sondern auch aufgrund besonderer klimatischer oder soziokultureller Umstände ${ }^{68}$.

Die beiden schweren Dragonerregimenter wurden bis 1812 in Irland und England zum Küstenschutz und als Garnisontruppe verwendet; die beiden leichten Bataillőne nahmen an der erfolglosen Unternehmung des Generals Moore auf der Pyrenäischen Halbinsel sowie an der Expedition an die Schelde teil. Das 3. Linienbataillon war von 1808 bis 1813 auf Sizilien stationiert, wo es zwar an einigen kleineren Unternehmungen beteiligt war, aber den größten Teil der Zeit in verhältnismäßiger Ruhe verbringen konnte. Andere Truppenteile, wie das 1. Husarenregiment befanden sich zwischen 1807 bis 1815 fast dauernd im Einsatz. Die Bedingungen, unter denen Verluste eintraten, und auch deren Umfang waren sehr verschieden. Außerdem spielte die Entfernung vom Depot der KGL, zu dem zunächst alle Rekruten geschickt wurden, eine Rolle. Für in England stationierte Ein-

66 Vgl. HStA Hannover, Hann. 38 D, Nr. 143. Dieser Bestand enthält eine Vielzahl Bittbriefe um Anstellung in der KGL. Ebenso Hann. 38 D, Nr. 94.

67. Einheiten der Legion waren beteiligt an der Expedition nach Hannover 1805/6: 1.-3. FußBatt., 1. und 2. reitende Batt., 1. Drag. Regt, 1. Husaren Rgt., 1. und 2. 1. Bat., 1.-5. Linienbataillon, an der Belagerung Kopenhagens und der Expedition ins baltische Meer 1807/8: 1. FußBatterie, 2. Fuß-Batt., 1. reitende Batt., 1.-3. Husaren Rgt., 1. und 2. 1. Bat., 3.-8. Linienbat., nahmen an den Feldzügen Wellingtons auf der pyrenäischen Halbinsel teil: 1. Fuß-Bat. stationiert in Lissabon, 2. Fuß-Bat., 4. Fuß-Batt., 1. und 2. 1. Drag. Rgt. (1812-1813), 1. Husaren Rgt. (1809-1813), 2. Husaren Rgt. (1810-1813), 3. Husaren Rgt. (1808-1809), 1. und 2. 1. Bat. (1808-1809, 1811-1813), 1., 2., und 5. Linienbat. (1808-1813), 7. Linienbat. (1808-1811), auf Sizilien waren stationiert. 3. (1808-1813), 4. (1808-1812), 6. (1808-1816) und 8. Linienbataillon (1808-1814), kämpften im südlichen Frankreich 1813/14: 2. Fuß-Batt., 4. FußBatt., 1. und 2. 1. Drag. Rgt., 1. Husaren Rgt., 1. und 2. 1. Bat., 1., 2., 4. und 5. Linienbat., an den Operationen im nördlichen Deutschland 1813/14 nahmen teil: 1. und 2. reitende Batt., 3. Husaren Rgt., Teile des 1., 2. und 5. Linienbat. und der beiden leichten Bat., an der Schlacht von Waterloo waren beteiligt: 1. und 2. Fuß-Batt., 1. und 2. reitende Batt., beide Drag. Rgt., 1. und 3. Husaren Rgt., 1. und 2. 1. Bat., 1.-5. und 8. Linienbataillon. Vgl. Schwertfeger, Geschichte (wie Anm. 3), Bd 1, S. 153-180.

68 Große Verluste traten bei den auf der Insel Walcheren eingesetzten leichten Bataillonen der Legion durch das dort herrschende feuchte Klima ein. Vgl. dazu Beamish, Geschichte (wie Anm. 2), Bd 1, S. 245-247 und Schwertfeger, Geschichte (wie Anm. 3), Bd 1, S. 218. Gerade für die auf Sizilien stationierten Einheiten scheint Alkoholismus ein großes Problem gewesen zu sein. Der Anstieg und die große Verbreitung von Geschlechtskrankheiten führte u.a. dazu, daß die Mannschaften in regelmäßigen Abständen durch die Legionsärzte svisitiert< wurden. Vgl. dazu HStA Hannover, Hann. 38 D, Nr. 815: Journal des 3. Linienbataillons. 
heiten konnten innerhalb von Tagen Ersatzmannschaften und Offiziere in Marsch gesetzt werden, um entstandene Lücken zu füllen. Bis die Meldung über Verluste von Sizilien nach England gelangte und die dort verschifften Mannschaften im Mittelmeer ankamen, verging oft mehr als ein halbes Jahr.

Weder die Entfernung zum Depot noch die Höhe der Verluste hätten ein Problem dargestellt, wenn hannoversche Landeskinder noch zu rekrutieren gewesen wären. Nach der zumindest militärisch erfolglosen Expedition nach Hannover und der Wiedereinschiffung der Truppen im Februar 1806 konnte die Werbung noch einige Zeit fortgesetzt werden, bevor die Preußen Hannover besetzten. Decken, der sich bis März in Hannover aufhielt und innerhalb dieses Monats weitere 500 Rekruten nach England schicken konnte, begab sich nach der preußischen Besetzung nach Stralsund und setzte von dort die Werbung fort ${ }^{69}$. Die preußische Administration ging eindeutig schärfer als die Franzosen gegen englische Werber vor, indem sie jedem Werber mit harter Bestrafung drohte und für die Gefangennahme eines solchen eine Belohnung aussetzte ${ }^{70}$. Im Sommer 1806 wurde, nachdem Decken Stralsund verlassen hatte, die Rekrutierung auf dem Kontinent eingestellt. Damit war endgültig klar, daß weitere Anwerbungen nur aus anderen Quellen gespeist' werden konnten. Die Anwerbung neuer Rekruten zum Ausgleich von Verlusten stellte kein drängendes Problem dar, solange die auszugleichenden Verluste nicht allzu groß waren. Allerdings konnte jetzt der Plan, die KGL auf eine Gesamtstärke von 20000 Mann zu bringen, dem das War Office Ende 1805 zugestimmt hatte, nicht mehr verwirklicht werden ${ }^{71}$.

Zwischen Ende 1806 und 1813 wurden in größerer Zahl nur Kriegsgefangene und Deserteure der unter französischem Befehl stehenden Einheiten in die KGL übernommen. Eine Ausnahme davon bildeten die ehemaligen dänischen Soldaten, die während und nach der Belagerung Kopenhagens 1807 angeworben wurden. Einigen Hannoveranern gelang auf abẹnteuerlichsten Wegen zwar immer noch die Flucht nach England, um der westfälischen oder französischen Konskription zu entgehen, doch ist die Zahl dieser Legionäre für die Geschichte der KGL unerheblich ${ }^{72}$. Die Werbung von Deserteuren und Kriegsgefangen fand entweder in den Einsatzgebieten direkt oder den Kriegsgefangenenlagern in Großbritannien statt. Allerdings scheint ihre Werbung in größerem Umfang nicht vor 1810 nötig und genehmigt worden zu sein. Die Geworbenen wurden in der Regel dem britischen General-Depot überwiesen und von dort an die Einheiten verteilt ${ }^{73}$. Eine Ausnahme bildeten die auf Sizilien stationierten Bataillone, weil sie die Angeworbenen als Soldaten der KGL direkt annehmen durften.

Gray, Prisoners, Wanderers, and Deserters (wie Anm. 59), S. 152.

Vgl. Wilhelm Havemann, Das Kurfürstentum Hannover unter zehnjähriger Fremdherrschaft 1803 bis 1813 , Jena 1867, S. 31.

71 Vgl. HStA Hannover, Hann. 38 D, Nr. 5, Pag. 132: Herzog von Cambridge an den Herzog von York, 5.12.1805.

Zwischen 1808 und 1810 sind auf den Werbebrief Deckens angeblich nur 41 Mann für die KGL geworben worden. Vgl. Listen und Nachweisungen (wie Anm. 42), S. 250. Diese Zahl scheint mir eindeutig zu niedrig zu sein. Heinecke nennt höhere Zahlen, seine Erinnerungen sind aber nicht nachprüfbar und manche Aussagen erscheinen fragwürdig. Vgl. Friedrich Heinecke, Meine Abenteuer als Werber gegen Napoleon, bearb. von Robert Walther, Hamburg 1925, S. 37 und 41. Einen weiteren Hinweis auf organisierte Werbung im nördlichen Deutschland nach 1808 gibt Johannes Müller, Eichsfelder in der EnglischDeutschen Legion 1803-1816, Heiligenstadt 1921, S. 5.

Vgl. Schwertfeger, Geschichte (wie Anm. 3), Bd 1, S. 228. 


\section{Werbung in den Einsatzgebieten}

Um das 1807 noch neutrale Dänemark daran zu hindern, mit seiner Flotte den Zugang zur Ostsee zu blockieren und damit unter anderem die für Großbritannien lebensnotwendige Versorgung mit Holz zu unterbinden, wurden Marineeinheiten in Marsch gesetzt und Truppen zur Landung in Dänemark verladen. In der Nacht vom 15. auf den 16. August wurde mit der Ausschiffung der Truppen begonnen, zu denen auch die beiden leichten, alle 8 Linienbataillone, die drei Husarenregimenter, die 1., 2. und 4. Fußbatterie und die 1. reitende Batterie der KGL gehörten. Bereits am 17. war Kopenhagen eingeschlossen worden ${ }^{74}$. Die weiteren militärischen Ereignisse sollen uns hier nicht weiter kümmern - das Ergebnis dieser Expedition war, daß Kopenhagen zur Kapitulation gezwungen und die dänische Flotte an Großbritannien ausgeliefert wurde. Die KGL verlor etwa 10 Prozent ihrer Soldaten durch Verluste in den Gefechten, Desertionen und Schiffbruch. Der Gesamtverlust belief sich auf 36 Offiziere und 1139 Mannschaften und Unteroffiziere, davon 5 Offiziere und 58 Mann durch Krankheit. Es desertierten 323 Mann, 4 wurden vermißt ${ }^{75}$. Durch Schiffbruch verloren insgesamt 456 Soldaten ihr Leben ${ }^{76}$. Die KGL konnte während der Expedition nach Rügen und Dänemark ihre Reihen zum ersten Mal durch Deserteure und Kriegsgefangene füllen. Hierbei handelte es sich in erster Linie um Dänen, Schweden, Preußen und Hannoveraner, die nach der Auflösung der kurhannoverschen Armee in die dänischen Streitkräfte eingetreten waren. Als Rekruten der KGL konnten im Zeitraum vom 30. Juli bis 18. Oktober 18071498 Mann angeworben werden ${ }^{7}$. Damit verblieb, abzüglich der Verluste, immer noch ein Überschuß von 323 Mann.

Anfang des Jahres 1810 hatten die meisten Einheiten der KGL Verluste erlitten, die ihre Stärke erheblich herabsetzten und durch die in den Depots anwesenden Rekruten nicht mehr voll ausgeglichen werden konnten ${ }^{78}$. Außerdem mußte nun auch immer mehr auf Rekruten anderer Nationalitäten zurückgegriffen werden. Deutlich wird dies in einem Brief des Rittmeisters Ernst v. Linsingen (3. Husaren-Regiment) an den Generalmajor Carl Christian v. Linsingen ${ }^{79}$. Linsingen schien stillschweigend davon auszugehen, daß die Hannoveraner und andere Deutsche unter seinen Leuten nicht in die Versuchung gerieten, zum Feind überzulaufen. Er mißtraute den Ausländern, sah aber auch, daß die Verluste durch Hannoveraner nicht mehr ausgeglichen werden konnten. Unter den englischen Kameraden mußte sich diese Erkenntnis erst noch durchsetzen.

Die Zahl der Kriegsgefangenen in britischem Gewahrsam stieg mit zunehmender Dauer des Krieges und damit auch die Zahl der Deutschen, die möglicherweise von der KGL geworben werden konnten. Jeder Deutsche, der bereit war,

74 Zu den Vorgängen, die zur Expedition nach Dänemark führten und dem Ablauf der Ereignisse dort vgl. Schwertfeger, Geschichte (wie Anm. 3), Bd 1, S. 89-116; Beamish, Geschichte (wie Anm. 2), Bd 1, S. 108-141 und Authentic Account of the Siege of Copenhagen, London 1807.

75 Vgl. Schwertfeger, Geschichte (wie Anm. 3), Bd 1, S. 120.

76 Vgl. ebd., Bd 2, S. 190.

77 Vgl. Beamish, Geschichte (wie Anm. 2), Bd 1, S. 535.

78 Vgl. Gray, Prisoners, Wanderers, and Deserters (wie Anm. 59), S. 153.

79 Vgl. HStA Hannover, Hann. 38 D, Nr. 237, Pag. 194: Ernst v. Linsingen an Carl Christian v. Linsingen, 17.6.1810. 
unter britischer Fahne zu dienen, wurde ebenso wie Kriegsgefangene anderer Nationalitäten vom Foreign Depot zu britischen Regimentern überwiesen. Nur mit ausdrücklicher Erlaubnis des Commanders in Chief war es der KGL möglich, unter den Kriegsgefangenen zu rekrutieren ${ }^{80}$. Direkte Rekrutierung unter den Kriegsgefangenen wurde durch den Herzog von Wellington auf der pyrenäischen Halbinsel erst im Frühjahr 1810 erlaubt. Die Angeworbenen sollten nicht wieder in Spanien oder Portugal dienen, da man befürchtete, sie könnten mit ihrem Wissen und der Ausrüstung wiederum zu den Franzosen desertieren ${ }^{81}$. Allerdings scheint es hiervon auch Ausnahmen gegeben zu haben, wie die Rekrutierung durch ein Kommando des 2. Husarenregiments beweist.

Ähnlich wie bereits während der Expedition nach Norddeutschland 1805/6 wurden von der Truppe Kommandos mit einem oder zwei Offizieren und mehreren Unteroffizieren abgestellt, die Rekruten werben sollten. Für das 2. Husarenregiment war der Rittmeister August Friedrichs in der Nähe von Cadiz damit beauftragt worden. Er warb nicht nur unter Kriegsgefangenen, sondern auch Deutsche, die in spanischen Diensten standen. In einem Brief vom 4. Januar 1811 schildert er eingehend die Vorzüge seiner/ Rekruten, um dann auszuführen,

»daß ich hier den Musici Meister von dem Spanischen Regiment Canaria für's 2te Hus. Regt. als Musici Meister angeworben [...] ich habe ihn daher versprechen müßen daß wenn Euer Hochwohlgeb. - deren Prüfung er sich mit allen Instrumenten unterwirft - nicht diesen Posten zu geben geruhen - er beym 3ten oder einem anderen Regt. angesetzt zu werden wünscht [...] Einen Koch der bey dem Franz. General gedient hat, behalten wir hier als Meß Mann ${ }^{82}$ «

Dieser Koch wurde rekrutiert und seine Dienste sofort in der Messe des Regiments genutzt, obwohl er in französischen Diensten gestanden hatte. Auch die anderen Rekruten sollten nach Möglichkeit wieder zum Regiment kommen, damit man nicht auf schlechteren Mannschaftsersatz vom Depot in Lymington angewiesen war. Die werbenden Regimenter nutzten ihre Einflußmöglichkeiten, um vielversprechende Soldaten oder Musiker in ihre eigenen Reihen aufnehmen zu können. Mag es sich bei dem Koch, der sofort für die Offiziermesse angestellt wurde, um eine Ausnahme handeln, auch andere Rekruten, die in Spanien und Portugal geworben worden waren, wurden nach der Transferierung ins englische Depot wieder auf die Peninsula versetz ${ }^{83}$.

Die Zustände, unter denen die französischen Truppen in Spanien leben und kämpfen mußten, waren so schlecht, daß Deserteure nur in Fetzen oder fast gänzlich unbekleidet zu den Briten überliefen. Die Rate der französischen Überläufer stieg ungeheuer, weil u.a. die Versorgungslage der britischen Truppen besser war.

Während der Mannschafts- und Unteroffiziersersatz bis auf wenige Ausnahmen ins englische Depot verschickt wurde, gestaltete sich die Einreihung von Offizieren wesentlich einfacher. Hatten diese Männer den >richtigen` familiären Hintergrund und die notwendige Bildung und entsprachen sie dem Bild, das beispielsweise August von dem Bussche von einem angehenden Offizier hatte, konnten sie direkt vom Cadetten zum Fähnrich aufsteigen. In einem Brief,

Vgl. Gray, Prisoners, Wanderers, and Deserters (wie Anm. 59), S. 153.

Vgl. HStA Hannover, Hann. 38 D, Nr. 9, Pag. 415: Brigademajor Timaeus an Col: Howard, 16.4.1810.

HStA Hannover, Hann. 38 D, Nr. 201, Pag. 3.

Vgl. ebd., Pag. 30. 
den er wahrscheinlich von der Isla de Leon aus St. Carlos im Mai 1811 absandte, beschrieb er diesen Vorgang und die Gründe, die ihn dazu bewegten, jemanden in seine Schwadron aufzunehmen, um ihm zum Offizierpatent in der KGL zu verhelfen:

"Seit dem 25ten d[ieses] M[onats] habe ich Michael Löning einen Kaufmanns Sohn aus Bremen wie Cadet angesetzet [...] Da er sich fürchtet französische Dienste nehmen zu müssen, wenn er zu seinem Vater zurück fehrt; so wünschte er in der Legion zu dienen, und da ich von Handelshäusern in Cadiz erfahren, daß sein Vater Vermögen hat; so habe ich ihn fürs Regiment engagiert, und werde dem General Alten Nachricht geben wenn er zeigen sollte, daß man ihn zum Officier gebrauchen $\mathrm{kann}^{84}$."

Löning eignete sich tatsächlich zum Offizier und wurde am 30. Juli 1811 gazettiert. Er nahm bis 1813 an den Einsätzen des 2. Husarenregiments auf der Peninsula teil und war auch an der Kampagne 1814 in den Niederlanden beteiligt.

Das Ersatzwesen der auf Sizilien stationierten Einheiten der KGL gestaltete sich etwas anders als auf der Peninsula. Wahrscheinlich aufgrund der langen Transportwege wurde es gestattet, direkt unter den Kriegsgefangenen und Überläufern zu werben. Beim 3. Linienbataillon, das seit März 1808 in verschiedenen Garnisonen auf Sizilien lag, wurden erstmals am 23. August 1809 Rekruten angenommen, die vorher Dienst im 3. und 4. Regiment des Königreichs Westfalen geleistet hatten. Am 11. April und 8. Juli 1810 erhielt dieses Bataillon wiederum Rekruten, die unter den Kriegsgefangenen geworben worden waren und zuvor unter französischer Fahne gedient hatten ${ }^{85}$. Auch hier wurden Kommandos unter dem Befehl eines Offiziers gebildet und mit der Werbung unter Kriegsgefangenen beauftragt. Am 9. November 1810 wurden der Leutnant von Heimburg, Sergeant Stümpel, Corporal Plagge und Corporal Schönhauser nach Menorca gesandt. Heimburg rekrutierte nicht nur für das dritte, sondern für alle auf Sizilien stationierten Bataillone der KGL ehemalige Soldaten der französischen Armee. Das detachierte Werbungskommando unter seinem Befehl kehrte am 11. Juli 1811 wieder zur Truppe zurück. Insgesamt sind im Jahre 181077 Mann für das 3. Linienbataillon geworben worden. Um jede Möglichkeit zu nutzen, Ersatz für die Bataillone der KGL auf Sizilien zu erhalten, wurde durch eine Brigade Order unter dem 12. Mai 1812 bekannt gemacht, daß alle Deutschen in sizilianischen Diensten in britische Dienste treten durften ${ }^{86}$. Die Verteilung dieser Freiwilligen sollte durch das Los gleichmäßig auf die vier auf Sizilien stationierten Bataillone erfolgen. Das dritte Linienbataillon nahm bis Ende des Jahres 1812192 ehemalige Kriegsgefangene und Überläufer in seine Dienste ${ }^{87}$.

Insgesamt wurden zwischen April 1810 und Juni 1813 auf der pyrenäischen Halbinsel 4138 Mann angeworben, während die auf Sizilien stationierten Bataillone ihre Verluste zwischen Dezember 1810 und Dezember 1814 durch die Rekrutierung von 1976 Mann ausgleichen konnten ${ }^{88}$.

Pag. 11.

Vgl. HStA Hannover, Hann. 38 D, Nr. 815: Journal des 3. Linienbataillons, Einträge vom 11.4.1809, 23.8.1809 und 8.7.1810.

86 Ebd., Eintrag vom 12.5.1812.

87 Ebd., Eintrag vom Dezember 1812.

88 Vgl. Listen und Nachweisungen (wie Anm. 42), S. 254. 


\section{Rekrutierung unter Kriegsgefangenen in England}

Da seit dem Frühjahr 1810 bereits auf Sizilien unter den in Spanien und Portugal übergelaufenen und gefangengenommenen ehemaligen Soldaten Napoleons geworben wurde, war es nur folgerichtig, die Werbung auch auf die Kriegsgefangenen in England auszudehnen. Ab Ende 1811 wurden von den Depots Kommandos in die größeren Lager auf der Insel gesandt, um Deutsche zur freiwilligen Meldung für die KGL zu veranlassen.

Diesen Kommandos, die sich aus mehreren Offizieren und langgedienten Unteroffizieren zusammensetzten, wurden ganz bestimmte Kriegsgefangenlager zugewiesen. Major David Martin vom 2. leichten Bataillon der KGL sollte die Werbung in den Depots in Portchester und Portsmouth betreiben; Major Brückmann, der aus Bexhill kam, war für die Depots in Chatham, Harlow, Plymouth, Stapleton, Valleyfield und Dartmoor zuständig. Unterstützt wurde er von den First Lieutnants Ludwig Jasper und Wilhelm v. Schade sowie zwei Sergeanten. In Norman Cross warben unter Major Martin, der Hauptmann Ernst von Düring, Leutnant Wilhelm von Heimbruch und vier Sergeanten, vier Corporale und zehn Soldaten, alle Angehörige des 1. leichten Bataillons der KGL ${ }^{89}$. Mit dem dritten Kommando sollte Major v. Linsingen vom 3. Husarenregiment aus Ipswich in Norman Cross der Werbung nachgehen ${ }^{90}$.

Die Instruktionen, nach denen sie Rekruten für die KGL anwerben durften, sahen vor, nur Deutsche, Österreicher, Preußen und Holländer aufzunehmen. Zu den hier Genannten wurden auch Belgier ${ }^{91}$, Polen und Schweizer gerechnet. Ausdrücklich untersagt war die Aufnahme von Franzosen, Italienern, Dänen, Schweden und Russen. Die Rekruten sollten nach ihrer Aufnahme zur Depot Company auf der Isle of Wight in Marsch gesetzt werden, um von dort auf die Einheiten der KGL verteilt zu werden. Vom Tag ihrer Aufnahme sollten die Rekruten ihren Lohn erhalten ${ }^{92}$. Nachdem die Werber an ihrem Bestimmungsort eingetroffen waren, machten sie sich mit den örtlichen Gegebenheiten vertraut. Die Möglichkeiten der Unterbringung der Rekruten mußte geklärt werden, ebenso, ob eine britische Amtsperson zu Verfügung stehen würde, die bei Eidesleistung der Rekruten als Zeuge fungieren konnte ${ }^{93}$.

89

90

1 Hier der Einfachheit so benannt, da die Herkunftsgebiete der Angeworbenen innerhalb des Staatsgebietes des heutigen Belgiens lagen. In den Meldungen der Werbeoffiziere wird differenziert zwischen `Flemings‘, 'Brabantern`, Männern aus Liége und anderen Orten des heutigen Belgiens.

92 Vgl. HStA Hannover, Hann. 38 D, Nr. 121, Pag. 13/14: Proposal for inlisting Recruits from among the Prisoners of War in England, for the King's German Legion.

93 Im Formblatt zur Eidesleistung der Rekruten heißt es: "einer der königlichen Friedensrichter von [hier ist der Ort einzutragen] attestiere hiermit dasz [es folgen Name und Beschreibung des Rekruten, sowie das Datum] dasz er sich freiwillyg für ein Handgeld von [Summe] hatte anwerben lassen, in der Armee Seiner königlichen Majestät, für die Zeit von [Zeitraum] Jahren, von diesem Tage an; und sollte Gross-Britannien nach Ablauf solcher Zeit im Kriege verwickelt seyn, so williget er ein ohne ferners Handgeld, noch sechs Monathe nach der Ratification eines definitiven oder endlichen Friedens zu dienen. Und ich attestiere ferner, dasz in meiner Gegenwart die zweyte und sechste Abtheilung der Kriegsartikel, gegen Aufwiegelung und Desertion ihm vorgelesen worden; dasz er den Eid der Treue geschworen, welcher in dem Gesetze, vom 39 Jahre der Regierung Königs Georg des Dritten, Capitel 109. Vorgeschrieben, anstatt des Eides, welcher in den besagten Kriegsartikeln benannt ist, und auch den Eid als wie oben, und dasz er die Summa von [Zahl] erhalten wie er eingeschworen wurde." HStA Hannover, Hann. 38 D, Nr. 121, Pag. 32. 
Außerdem sollte ein Surgeon zur Stelle sein, um die Rekruten zu untersuchen. Hauptmann Ernst v. Biela schilderte die vorgefundenen Verhältnisse in der Umgebung von Norman Cross in einem Bericht an den kommandierenden Oberst des 3. Husarenregiments, Generalleutnant Carl v. Linsingen, vom 3. November $1811^{94}$.

Der wichtigste Gesichtspunkt war die jeweilige Anzahl der in Gefängnissen oder auf Prison Ships eingepferchten Gefangenen. Natürlich interessierten sich die Werbeoffiziere für die landsmannschaftliche Zusammensetzung in den Gefängnissen. Biela erhielt vom zuständigen britischen Offizier, Captain Traper, eine Liste der in Norman Cross eingesperrten Kriegsgefangenen, die durch die KGL angeworben werden durften. Insgesamt hatte Traper 479 Mann aufgelistet, worunter die Belgier mit 375 Mann die größte Gruppe stellten. In weitem Abstand folgten 46 Deutsche, die aus den französisch besetzten Gebieten auf der linken Seite des Rheins stammten, 22 Preußen aus der Gegend zwischen Bremen und Emden, 20 Holländer, 9 Schweizer, 5 Österreicher und 2 Polen $^{95}$. Nachdem Biela die nötigen Auskünfte von Traper erhalten hatte, begab er sich selbst in das Kriegsgefangenenlager Norman Cross und wurde dort sofort von einigen Gefangenen um Hilfe gebeten. Nachdem er sie in Augenschein genommen und sich über die dortigen Zustände informiert hatte, wies er nochmals auf die äußerst schlechte Kleidung der Gefangenen hin. In dieser Kleidung waren Rekruten unmöglich in Marsch zu setzen, darum sollte unbedingt ein Depot von Hemden, Hosen und Schuhen angelegt werden. Insgesamt scheint die Kleidung der Kriegsgefangenen nicht nur in Norman Cross äußerst fadenscheinig gewesen zu sein; so schrieb Major Martin aus Fort Cumberland an Friedrich v. d. Decken im November 1811: »die Recruten aus den Prisons sind mehrentheils alle nackend, und bedürfen besonders Hemde, Schue, Strümpfe, Kappen, und einzelne auch ein Casket ${ }^{96} . "$

Übereinstimmend wiesen die Werbeoffiziere darauf hin, daß die Rekruten, nachdem sie durch einen Surgeon visitiert und angenommen worden waren, nicht wieder mit ihren früheren Kameraden zusammenkommen dürften, da sie insbesondere von den Franzosen ob ihrer Meldung für den britischen Dienst mißhandelt würden. Zudem wollte man sie nicht dem Spott anderer Gefangener aussetzten ${ }^{97}$. Biela schlug daher vor, die Werbung in den Lagern folgendermaßen zu handhaben: Der Werbeoffizier sollte mindestens 30 bis 40 Mondierungen mit sich führen, um die Gefangenen einzukleiden. In einem Zimmer des Kriegsgefangenenlagers sollten die Gefangenen befragt werden, ob sie in die KGL eintreten wollten, während durch einen Surgeon gleichzeitig ihre Tauglichkeit überprüft werden konnte. Nach der Annahme durch Werbeoffizier und Surgeon sollte der Rekrut gekleidet und aus der Baracke geführt werden. Ein Zusammentreffen mit seinen ehemaligen Kameraden sollte vermieden werden ${ }^{98}$.

Das Verhältnis zwischen den Kriegsgefangenen, die in fremde Dienste traten und denen, die zurückblieben, ist zu allen Zeiten schwierig gewesen. Die gleichen Probleme finden wir zur Zeit des amerikanischen Sezessionskrieges ebenso wie

Vgl. HStA Hannover, Hann. 38 D, Nr. 122, Pag. 30, Ernst v. Biela an Carl v. Linsingen, 7.12.1811.

Ebd., Pag. 32: Ernst v. Biela an Carl v. Linsingen, 13.12.1811.

Ebd., Pag. 5: David Martin an Friedrich v.d. Decken, 3.11.1811.

Ebd., Pag. 33: Ernst v. Biela an Carl v. Linsingen, 22.12.1811 und Pag. 7: David Martin an Friedrich v.d. Decken 4.3.1812.

Vgl. ebd., Pag. 33: Ernst v. Biela an Carl v. Linsingen, 22.12.1812. 
während des Zweiten Weltkrieges bei der Werbung von Freiwilligen für die Waffen-SS. Interessant an den Ausführungen Bielas ist der letzte Satz: Hier begegnet uns wieder der Effekt, den sich die Werber von zur Schau gestellten ransehnlichen Leuten in schönen Uniformen versprachen. Auf die gleiche Weise wurde schon während der Expedition nach Norddeutschland 1805/6 geworben ${ }^{99}$. Heimliche Werber mußten andere Lockmittel einsetzen.

"Ich zeigte ihnen feine, vortrefflich kolorierte Kupferstiche, auf denen englische Husaren, Dragoner und Artilleristen auf stolzen Pferden, und Linientruppen in ihren roten Uniformen schimmernd abgebildet waren. Die Bilder waren wirklich so schön und verführerisch, daß manche der kühnen Gesellen [...] bei ihrem Anblicke ausriefen: Saun Keerl möchte eck ook sin!, ${ }^{100 . " ~}$

Obwohl Heinecke in vielen seiner sonstigen Ausführungen nicht vertrauenswürdig erscheint, trifft diese Beschreibung doch im allgemeinen zu und schildert eindrucksvoll den Effekt, den Bilder von Uniformen auf die Handwerksgesellen machten. Besonders attraktiv wirkten nicht allein die Uniformen, hinzu kam sicherlich der Wunsch, einer ruhmreichen Truppe anzugehören, das ansehnliche Handgeld und nicht nur gut bezahlt, sondern auch verpflegt und gekleidet zu werden. Im Unterschied zu den Kriegsgefangenen mag auch eine eher romantische Vorstellung vom Soldatenleben bei der Anwerbung von niedersächsischen Handwerksgesellen und Bauernsöhnen eine Rolle gespielt haben. Um wieviel mehr mußte eine ähnliche Vorgehensweise auf Kriegsgefangene wirken, die schlecht gekleidet, mangelhaft ernährt und in drangvoller Enge in Gefängnissen und Prison Ships untergebracht waren. Dazu kam noch, daß nicht alle Deutschen in französischen Diensten freiwillig oder mit Freuden für das Kaiserreich gedient hatten. Unter den Kriegsgefangenen in Norman Cross, Portchester oder Plymouth werden viele Konskribierte der westfälischen Armee gewesen sein, die nicht lange überredet werden mußten, in britische Dienste zu treten, zumal wenn sie dort von Offizieren kommandiert wurden, die nicht nur Deutsch sprachen, sondern zum Teil auch aus der Heimat der Angeworbenen stammten ${ }^{101}$. Die Werbung verlief sehr erfolgreich, denn Martin konnte am 19. April melden, daß er insgesamt 529 Rekruten aus Portchester und Portsmouth geworben hatte. Davon sollten 65, unter denen sich 41 Deutsche, 18 Belgier, 3 Österreicher, 2 Polen und ein Preuße befanden, der Kavallerie der KGL überwiesen und zum Depot nach Ipswich geschickt werden. Die restlichen 464 waren für die leichten und Linienbataillone bestimmt und marschierten nach Bexhill. Auch hier stellten die Deutschen mit 241 Mann die größte Gruppe, gefolgt von 84 Belgiern, 51 Holländern, 33 Preußen, 27 Polen, 15 Österreichern und 13 Schweizern ${ }^{102}$.

Ähnliche Erfolge konnte Brückmann melden. Bis zum 7. Juni 1812 hatte er 293 Mann geworben, davon waren 242 Deutsche, der größte Teil Hessen-Darmstädter, einige Männer aus dem Elsaß, aus Trier, der Pfalz und sogar ein Hannoveraner. Die restlichen 51 Mann setzten sich zusammen aus Belgiern (45), Holländern (3),

99 Vgl. Anm. 53.

100 Heinecke, Meine Abentuer als Werber gegen Napoleon (wie Anm. 72), S. 20.

101 Vgl. HStA Hannover, Hann. 38 D, Nr. 201, Pag. 24. Deutlich wird dieser Punkt in einem Brief des Rittmeisters Friedrichs, der sich auf ein durch britische Offiziere aufgestelltes Bataillon aus Kriegsgefangenen und Deserteuren bezieht. Möglicherweise handelte es sich bei diesem Bataillon um die >German Deserters', von denen Wellington in einem Brief an Generalleutnant Graham vom 31.12.1810 sprach. Vgl. Charles Oman, A History of the Peninsular War, Vol. 4, London 1996, S. 98.

102 Vgl. HStA Hannover, Hann. 38 D, Nr. 122, Pag. 19. 
Preußen (2) und einem Polen. Es handelte sich durchweg um langgediente Soldaten, die Dienstzeit variierte zwischen 1 1/2 und 16 Jahren. Der größte Teil der Männer (195) stand vor ihrer Gefangennahme bei der Hessen-Darmstädter Infanterie, drei waren Artilleristen, 79 hatten in der französischen Armee gedient, 67 bei der Infanterie und die restlichen 12 bei der Kavallerie, einer kam von der Kaisergarde, einer war Fahrer beim Artillerie-Train und der oben erwähnte Pole gehörte der polnischen Legion an. Zum Transport der Rekruten waren bereits am 5. Juni zwei Offiziere und vier Unteroffiziere aus Bexhill angekommen, die die Männer auf ihrem Weg nach dorthin begleiten sollten ${ }^{103}$.

Nach Abschluß der Werbung in England im März 1814 hatte die KGL 1978 neue Rekruten erhalten ${ }^{104}$. Aber nicht nur die KGL hatte von der Werbung unter Kriegsgefangenen in England profitiert: Einige ihrer Offiziere waren abgestellt worden, für das 60. britische Regiment, die Royal Americans, zu werben. Zur Werbung wurde unter anderem ein Kommando unter Hauptmann Schlüter gebildet, zu dem auch die Fähnriche Nagel und Bronckhorst sowie drei Sergeanten gehörten, das im Depot in Valleyfield werben sollte ${ }^{105}$. Auch hier ließen sich Kriegsgefangene in großer Anzahl anwerben, so daß mehrere neue Bataillone aufgestellt und sogar an die anderen Foreign Corps noch Rekruten überwiesen werden konnten ${ }^{106}$.

\section{Zusammenfassung}

Die Aufstellung und Werbung der KGL verlief nach dem traditionellen Muster, das England am Ende des 18. und zu Beginn des 19. Jahrhunderts anwandte, um Fremdtruppen zu bilden und ihre Einsatzstärken zu sichern.

Die Erteilung eines Werbebriefes an Friedrich v.d. Decken bildete den Anfang, die Auflagen und Vorschriften, die er zu beachten hatte, waren durchaus mit denen zu vergleichen, die Colin Halkett auferlegt wurden. Im Gegensatz zu Letzterem allerdings hatte Decken ein ganz besonderes Rekrutierungspotential zur Aufstellung der KGL im Auge: Die Soldaten der aufgelösten kurhannoverschen Armee. Obwohl anfangs auch in größerem Umfang Ausländer geworben wurden, strömten ab Ende 1803 ehemalige Soldaten der kurhannoverschen Armee und andere Hannoveraner nach England, um sich für den Dienst in der KGL zu verpflichten.

Möglich wurde dies unter anderem durch den Aufbau einer Organisation zur Werbung und Weiterbeförderung von Rekruten durch das französisch besetzte Kurfürstentum via Hamburg - Husum - Helgoland bis nach England. Hier liegt sicherlich eine der Besonderheiten, die bei der Aufstellung der KGL ins Auge fallen. Obwohl auch Werber anderer Einheiten im Norddeutschen tätig waren, hatte die KGL doch den Vorteil auf persönliche Beziehungen zwischen den ehemaligen hannoverschen Soldaten zurückgreifen zu können, von denen ausgiebig Gebrauch gemacht wurde.

103 Ebd., Pag. 78.

104. Vgl. Listen und Nachweisungen (wie Anm. 42), S. 254.

105 Vgl. HStA Hannover, Hann. 38 D, Nr. 120, Pag. 260.

106 Vgl. Beamish, Geschichte (wie Anm. 2), Bd 2, S. 536. 
Obwohl im Hannoverschen nur heimlich geworben werden konnte, schritt die Aufstellung eines Korps aller drei Waffengattungen bis 1805 schnell voran. Die Expedition nach Hannover Ende 1805 bescherte der KGL dann noch einmal einen solchen Zustrom an Rekruten, daß die Aufstellung von zwei Kavallerieregimentern, drei vollständigen Infanteriebataillonen sowie einer weiteren Batterie möglich wurde. Durch die politische Lage (Preußische Okkupation des Kurfürstentums, Krieg mit Dänemark, schärfere Überwachung durch die Franzosen) war es ab 1806/7 nicht mehr möglich, im Kurfürstentum Rekruten in größerer Zahl zu werben. Um Einsatzverluste auszugleichen wurden jetzt Rekruten entweder direkt in den Einsatzgebieten oder in Kriegsgefangenenlagern in England geworben. Dabei wurden geborene Deutsche, in erster Linie ehemalige Angehörige unter französischem Kommando stehender Rheinbundtruppen bevorzugt angenommen, aber auch Männer aus fast allen anderen europäischen Ländern. An Bewerbern für Offizierstellen innerhalb der KGL herrschte nie Mangel, allerdings bleibt zu bemerken, daß im Gegensatz zur englischen Armee Stellenkauf in der KGL nicht üblich war und sich Beförderungen nach Eignung, Anciennität in der ehemaligen kurhannoverschen Armee und freien Stellen richtete.

Die Methoden der Werbung waren durchaus traditionell, mit Ausnahme der Aufstellungsphase, in der persönliche Kontakte im Vordergrund standen. Es wurde bereits ausgeführt, daß Offiziere, bevor sie nach England gingen, versuchten, Männer ihrer alten Einheiten zu überzeugen, ihnen dorthin zu folgen. Die heimlichen Werber benutzten den relativ hohen englischen Sold, das reichlich bemessene Handgeld und die farbenprächtigen Uniformen als Argument zur Einreihung in die KGL. Die besonderen Verhältnisse im besetzten Kurfürstentum erlaubten nur die heimliche Werbung. Ohne eine Organisation zur Weiterleitung der Rekruten wäre es kaum möglich gewesen, bis 1805 ein Korps aus drei Waffengattungen zu bilden. Das Netz der Werber erstreckte sich über ganz Hannover, und ohne die Unterstützung der Bevölkerung hätte es niemals als Sammelplatz für die Rekruten der KGL dienen können. Die Werber und die sie leitenden Offiziere bewiesen Findigkeit und Flexibilität, wenn es galt, Ausweichrouten zu finden oder den feindlich gesinnten Behörden ein Schnippchen zu schlagen. Diese Organisation zur Werbung von Männern aus dem besetzten Kurfürstentum erforderte nicht nur hohe finanzielle Zuwendungen, sondern auch organisatorisches Geschick beim Aufbau der gesamten Organisation, wie auch bei der Auswahl der shauptamtlichen`Werber.

Die Werbung in den Einsatzgebieten außerhalb Deutschlands und in den Kriegsgefangenenlagern unterschied sich kaum von der anderer Foreign Corps in englischen Diensten. Allerdings scheint die KGL bei der Auswahl der deutschen Rekruten bevorzugt behandelt worden zu sein. Zwischen 1803 und 1813 gelang es den Werbern der KGL immer wieder die Bataillone, Regimenter und Batterien mit genügend Rekruten zur Erhaltung ihrer Kampfkraft zu versorgen. Die einzige Ausnahme bildet hier das 7. Linienbataillon, das nach schweren Verlusten auf der Peninsula aufgelöst wurde. Die verbliebenen Mannschaften wurden unter die anderen Bataillone der KGL verteilt, während Offiziere und Unteroffiziere nach England gingen, um das Bataillon neu zu formieren. Während die Einheiten in Portugal und Spanien auch immer wieder Ersatz aus den Depots in England erhielten, waren die auf Sizilien stationierten Einheiten in erster Linie darauf angewiesen, im Einsatzgebiet und den Kriegsgefangenenlagern der Umgebung ihren Mannschaftsbestand zu ergänzen. 